\title{
ENTRE OS VARADOUROS DA HISTÓRIA E OS MEANDROS DA MEMÓRIA DO RIO PURUS
}

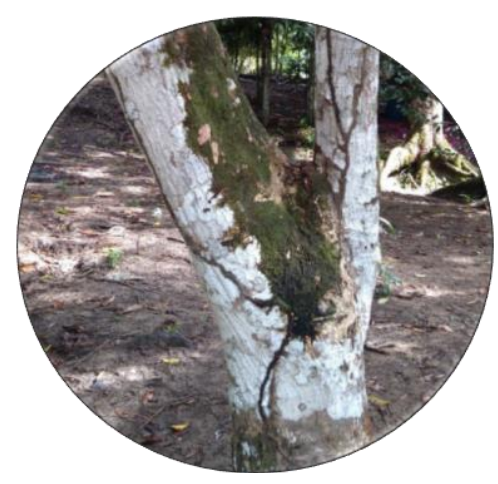

Antonio Alexandre Isidio Cardoso' Admilton Freitas das Chagas Filho ${ }^{2}$

\section{Resumo}

Com base em discussões que cruzam história e memória, este artigo tem por objetivo tratar dos enlevos do passado presente do rio Purus. Foram trabalhadas várias fontes, como testemunhos orais e documentação oficial escrita, coletadas em ocasião da Expedição Purus, que viajou pelo rio entre janeiro e março de 2012, composta por um grupo multidisciplinar de pesquisadores.

Palavras-chave: História. Memória. Purus

\begin{abstract}
Based on discussions that cross history and memory, this article aims investigate the past present of the Purus River. We analized oral testimonies and official documentation collected at the time of the Expedition Purus, that traveled the river between January and March 2012, consists of a multidisciplinary group of researchers.
\end{abstract}

Keywords: History. Memory. Purus

\footnotetext{
${ }^{1}$ Doutor em História Social (USP)

${ }^{2}$ Cientista Social (UFAM)
} 


\section{INTRODUÇÃO}

A história e a memória são faces opostas de uma mesma moeda. Ambas são produzidas no presente e se referem a acontecimentos passados, mesmo sendo diferentes em suas composições de sentido. Elas guardam fronteiras porosas entre si, pois toda base de pesquisa histórica tem lastro em artefatos de memória, que, por sua vez, pode se utilizar das narrativas historiográficas para alinhavar suas tramas. A história tem suas metodologias de trabalho, seus desencadeamentos e arroubos de ciência, já a memória se compromete especificamente com as formas de lembrar (ou esquecer) o vivido. Portanto, são distintas, embora possuam um vínculo indissolúvel e dialético.

É diante desses jogos de luz e sombra que pensamos a história e a memória do Purus. Neste artigo serão tratadas algumas questões de fundo do processo de interiorização da frente extrativista a partir do século XIX no rio, sem perder de vista seus desdobramentos contemporâneos nas experiências dos que vivem o tempo presente, contemplando suas narrativas e memórias. As fontes utilizadas foram levantadas em ocasião da Expedição Purusi ${ }^{\mathrm{i}}$ empreendida por um grupo multidisciplinar de pesquisadores, que se concentrou no médio curso do rio entre as cidades de Tapauá, Canutama e Lábrea, entre janeiro e março de 2012. Dentre as várias frentes de pesquisa exploradas, consubstanciava-se uma preocupação com o levantamento de acervos documentais sobre o Purus, que incluía tanto fontes escritas como entrevistas com interlocutores e portadores de memórias sobre o rio. Foi com esse foco que a pesquisa foi iniciada já nos itinerários de barco a partir de Manaus, oportunidade ímpar de acompanhar os fluxos que ainda hoje fazem parte do cotidiano dos habitantes do Purus. 


\section{História e memórias embarcadiças}

Seria de grande presunção tentar auscultar e entender todos os olhares que já foram voltados ao Purus a partir de embarcações. Muitos foram os que navegaram e viveram a experiência de conhecer os tortuosos meandros do rio. Mas poucos ficaram registrados, a maioria composto pela roupagem do mundo letrado, principalmente no século XIX. São falas preocupadas com rotas comerciais, questões políticas e territoriais, conflitos com povos indígenas, produtos da floresta, dentre outros temas, produzidas, em seu maior contingente, por órgãos oficiais e também por casas comerciais ${ }^{\text {ii }}$. Esse cenário longe de impedir a análise de outros sujeitos (que mesmo silenciados teimam em aparecer) traduz-se num desafio do ponto de vista metodológico para o pesquisador da História.

Entendemos que as experiências do passado não se perdem em sua totalidade com a fruição e a passagem do tempo, encarnando-se na fala dos vivos, como um substrato que atribui sentido e dialoga com o presente. Um importante vetor desse processo é a memória, que articula lembranças, acontecimentos, visões, sensações. Foi através de conversas com pessoas no barco, entrando em contato com suas reminiscências, que a concretude dessa reflexão veio à tona.

Um dos nossos interlocutores foi Sr. Francisco, 73 anos, que estava também no barco Vovô Osvaldo II, quando a Expedição Purus destinava-se à Tapauá. Nosso contato com ele começou numa madrugada de lua cheia, quando a embarcação começou a fazer movimentos incomuns, singrando o rio como se estivesse desviando de alguma coisa, com movimentos bruscos. Nesse momento algumas pessoas levantaram, e as redes interligadas, encostadas umas nas outras, começaram a balançar. Foi nessa ocasião que avistamos o Sr. Francisco debruçado sobre o parapeito do barco, fumando um cigarro de palha, e olhando fixamente para o rio. 
Buscamos dialogar com o Sr. Francisco e descobrimos que ele destinava-se à Lábrea, onde residia, e que naquela ocasião estava retornando de Manaus, onde fora fazer um tratamento de saúde, situação compartilhada por muitos dos tripulantes do Vovô Osvaldo II. Entrando mais na conversa, perguntamos se ele já havia viajado muitas vezes pelo Purus. Além da resposta afirmativa, ele começou a nomear algumas praias, explicando que em cada "volta" do rio existe um barranco e uma praia, sempre um oposto ao outro, nos falando ainda que o rio, em sua opinião, ainda iria encher muito, que as águas iriam crescer. Certamente tal vocabulário e conhecimento não adviriam de quem olha o Purus apenas como passante, de quem somente transpõe todos aqueles lugares.

Sua vida enquanto trabalhador fora atravessada pelo corte da seringa, pela retirada da sorva, e posteriormente do pau rosa, ofícios que foram descritos sem uma organização temporal precisa. Segundo sua fala, no passado havia uma grande quantidade de migrantes no Purus, em maioria cearenses, mas que hoje estes estão já "misturados", tornados amazonenses. Ele, logo depois, fez questão de traduzir tal "mistura", discorrendo sobre um processo no qual estavam inseridos todos os adventícios que chegavam em terras amazônicas, especialmente os que se destinavam a labuta na floresta. Os que chegavam, nos explicou Sr. Francisco, eram "brabos", pois não sabiam manobrar a canoa, desconheciam o manejo do corte das seringueiras, não entendiam os modos de pescar ou caçar da terra, estranhavam o clima, e até o regime de trabalho. Estes sujeitos passavam por uma espécie de escola, da qual Sr. Francisco fora muitas vezes professor. Após alguns meses de "aulas", quando os recém-egressos eram tutorados pelos já afeiçoados aos ritmos do trabalho da floresta, aos poucos, os "brabos" tornavam-se "mansos", ou seja, começavam a andar "com as próprias pernas" definitivamente, entendendo pelo menos algumas das feições da vida nas paragens amazônicas. 
O relato do velho tripulante do Vovô Osvaldo II imprime sentidos ao passado, articulados através da memória. É interessante perceber a sutileza dessas composições, cuja base está em arranjos, em seleções de experiências passadas, que se materializam no presente através das lembranças, que podem ser analisadas, ajudando a entender as tintas do vivido. O processo de "amansamento" descrito pelo Sr. Francisco pode ser encontrado em vários trabalhos, que dão vazão a argumentos semelhantes, como no texto de Eurípedes Funes, que utilizou algumas entrevistas coletadas nos anos 1940 por Samuel Benchimol (Benchimol, 1977). Entre os interlocutores havia um cearense que definiu seus sentimentos, suas sensações, numa frase bastante significativa, que serviu de mote para o trabalho de autor. "Quem vive no inferno se acostuma com os cães" (Funes, 2008).

Funes discute as noções de Eldorado e Inferno Verde historicamente através de experiências migratórias, que, segundo sua argumentação, também ajudaram a atribuir sentido a composição do que conhecemos como Amazônia. Tais referências comungam de conotações antípodas, que ora estabelece relação com uma ideia benfazeja, paradisíaca e enredada em riquezas, e ora mostra uma face maléfica, penosa, de uma vida de dificuldades. Tudo leva a crer que as experiências de deslocamento, do olhar a partir do barco, dos mundos do trabalho, dos estranhamentos e adaptações, foram ajudando a compor essas representações.

Essas facetas de atribuição de sentidos ao longo do tempo foram iniciadas com o deslocamento em embarcações, seja nas sumacas, que faziam navegação de cabotagem no período colonial, ou nos vapores que velozmente passaram a singrar águas amazônicas a partir do século XIX. Essas embarcações não carregavam apenas pessoas e mercadorias, mas também notícias, visões de mundo, impressões, experiências, que eram transmitidas a muitos outros sujeitos através do seu incessante movimento, de porto em porto. 
O testemunho do Sr. Francisco pode ser inserido dentro desse grande movimento. Seu olhar fixo voltado ao rio, suas falas e memórias, seu conhecimento sobre cada praia, cada barranco, sobre cada volta do Purus, carrega grandes fardos de historicidade. Ao detectar essa composição e refletir sobre tais questões percebe-se que a travessia do barco não se faz somente através das águas de um rio, pois também se vive uma viagem no tempo.

\section{História e memórias em terra firme}

Era por volta de 14 horas quando chegamos à Tapauá. Depois de três dias de viagem, após muitas conversas e expectativas, descemos no nosso primeiro destino em terra. A partir dessa ocasião a cidade começou a tomar forma. Situada em terra firme, no alto de um extenso beiradão, Tapauá se espraia em ruas asfaltadas, que serpenteiam ignorando qualquer precisão cartesiana. De cima é possível contemplar as inúmeras habitações flutuantes que emolduram a "orla", principalmente na parte que corresponde ao rio Ipixuna, que se encontra com o Purus logo à frente.

Inicialmente, buscamos mapear os sistemas produtivos que incluíam fluxos e arranjos sociais na cidade, inquirindo suas formas de organização. Nossas questões incidiam especialmente sobre a dinâmica dos roçados e da coleta de castanha, motes que caracterizam de maneira significativa a ocupação de muitas famílias, e que historicamente tiveram peso na conformação das várias formas econômico/sociais do campesinato amazônico. Foi nesse sentido que após nossa chegada contatamos um Sr. chamado Pedro, que na ocasião estava organizando uma farinhada e buscava reunir trabalhadores para dar cabo da empreitada. Percebemos, com algum tempo, que esse tipo de agenciamento não era incomum em Tapauá, onde proprietários habitualmente contratam famílias para produzir farinha. Segundo levantamos, Pedro, assim como muitos outros, acordava 
com os trabalhadores a produção através de "meia" (metade), ficando cada parte com $50 \%$, sendo a parcela das famílias muitas vezes vendida (total ou parcialmente) para os próprios patrões.

O circuito envolve inúmeras famílias, algumas dezenas de ribeirinhos e indígenas identificados como parentes distantes, primos e/ou compadres, e assim, o sistema de produção familiar também vai atendendo a demanda de escala comercial. Quando se trata da coleta de castanha também existe uma concatenação semelhante, tendo em vista que algumas famílias viajam para terras distantes de suas residências, muitas vezes através de agenciamento patronal, montando acampamento e fixando-se no castanhal durante os meses de coleta, retornando somente após o termino da temporada de extração da castanha.

As atividades reúnem trabalhadores, proprietários e atravessadores que movimentam o circuito da farinha e também da castanha, integrando, inclusive, relações sociais sedimentadas em várias gerações, envolvendo avós, pais e netos que atuam em parceria durante as atividades. Muitos testemunhos, nesse direcionamento, demonstraram com mais detalhes as tramas tecidas entres os habitantes do rio e os circuitos produtivos.

O Sr. Raimundo Nival (paroquiano da igreja de Tapauá) nos concedeu uma entrevista contando a vida de trabalho do padrasto, mãe e avó, que viveram grande parte de suas vidas pelo Purus. Os pais e a avós do Sr. Nival, migrantes vindos do que hoje chamamos de Nordeste, passaramlhe seus conhecimentos da labuta, sobre a retirada de madeira, o corte de seringa, do caucho, da castanha e muitas outras atividades produtivas. Nascido na comunidade Linda Vista, Raimundo Nival nos contou que começou a jornada de trabalho aos 07 anos de idade em 1943. Ao retratar o ensinamento sobre o corte das seringueiras, Nival se lembrou da jornada de trabalho confundindo-a com sua "educação", pois desde pequeno no seringal, no dia-a-dia da lida, passava a conhecer muito bem todo o processo de facturação do látex. 
(...) a gente ia rodando jogando o leite em cima e em baixo no buião, onde nós butava caroço de urucuri que era fumaça, aquela fumaça, o leite ia secando e você rodando o pau e jogando leite em cima rodando até acabar o leite, era desse tamanho assim mais ou menos quase da grossura de um tambor com uns oitenta quilo, cem quilo e dalí quando o patrão passava na época era o Raimundo marques e Zé Marques.iii

A sua narrativa expõe a história de vida de um seringueiro que explica todo o processo de elaboração da borracha desde o corte e defumação do látex até a modelação do rolo da borracha pronta. Exemplos como o de Nival são bastante comuns pelo Purus, inclusive entre a população indígena.

Além da fala do paroquiano, também conversamos com Francisco, índio Paumari, nascido na aldeia Manissuã, que descreveu-nos sua infância já em contato com os "brancos", trabalhando na coleta da castanha, no corte da seringa, da madeira, tirando óleos de copaíba, itauba, viróla, marupá e louro. Segundo Francisco:

...o índio (normalmente) não trabalha nessas coisas, somente se for incentivado pelo de fora - o trabalho do índio é pesca e o roçado, mas quando chegava o patrão incentivando, o serviço dava conta de a gente sobreviver retirando um tantinho de dinheiro (...) nós trabalha na agricultura aí trás para a cidade para vender e comprar as coisas necessárias para a aldeia, o rancho e o combustoliv.

Esta fala aponta questões sobre a condição dos indígenas diante desses circuitos, além de revelar algumas facetas das mudanças vivenciadas com a entrada do "branco" juntamente com o extrativismo de mercado.

Tais informações nos apresentaram índices analíticos bastante significativos, especialmente quando pensamos os vários desdobramentos das frentes extrativistas pelo rio. Assim, após essas primeiras impressões, 
buscamos também levantar as possibilidades de pesquisa no campo dos arquivos documentais, de modo a cruzar as referências coletadas. Em conversas com as pessoas que nos viam transitar na cidade, sempre entre uma pergunta trivial e outra (como uma orientação na rua, etc) questionávamos sobre possíveis locais de guarda de fontes, além de outros interlocutores possíveis. Muitos apontaram locais e pessoas que se repetiam a cada fala, sendo este um indicativo para continuar o caminho de pesquisa em Tapauá.

Seguimos para os locais de pesquisa mais citados, o primeiro foi o cartório da cidade, onde segundo sua Tabeliã (que recebeu nossa proposta com certa surpresa) havia pouco material histórico, tendo em vista que a história administrativa do município se encontra vinculada em sua produção documental à Canutama e Lábrea (somente a partir da segunda metade do século XX Tapauá foi adquirindo autonomia política). Mesmo assim, foi encontrado no cartório livros de registro de casamento de uma localidade chamada Itatuba, correspondente aos anos da década de 1900. Certamente, trata-se de uma espécie de distrito, do que à época era o território de Canutama.

Através da leitura de tal tipologia de fonte é possível examinar alguns índices analíticos, como a "naturalidade" dos noivos e seus pais, além da faixa etária dos que casavam, sendo possível observar através da ancestralidade e da idade, os locais de nascimento dos envolvidos (pais e filhos). Essas informações podem ser levantadas no sentido de examinar os fluxos de pessoas pelo Purus e alguns de seus arranjos matrimoniais. Lendo esses índices fica claro que a maioria das pessoas presentes na documentação não é de Itatuba, aparecendo alguns como "naturais" do estado do Amazonas, mas nascidos em outras localidades, sendo que a maioria figura como "filho" do Ceará (aparecendo ainda alguns de outros estados do que hoje chamamos de Nordeste). 
Não há um indicativo direto sobre as presenças indígenas nessas ocasiões, embora as fontes deixem brechas quando nomeiam alguns como "naturais" do Amazonas. Contudo, cumpre notar que, sendo a maioria dos registrados "filhos" de outros estados, percebe-se que a composição das uniões civis e as migrações de pessoas para o Purus apresentavam uma estreita relação.

Observando a origem masculina percebe-se que a maioria advém de outros lugares, não sendo possível afirmar o mesmo para as mulheres, pois muitas aparecem como "naturais" do Amazonas. Isto demonstra uma das facetas do fluxo migratório que se conformava desde longa data, mas que engrossou suas fileiras nas três últimas décadas do século XIX, onde a maioria dos que empreendiam a travessia eram homens. $O$ caráter eminentemente masculino dessas migrações permite denotar que nos casamentos ocorridos em Itatuba muitas das mulheres já viviam na localidade, restando questionar sua origem. Algumas já eram filhas de migrantes, como a própria fonte indica numa breve observação da naturalidade de seus pais, mas algumas outras não, o que permite inferir a possibilidade de sua origem ser indígena. Resta investigar, diante dessa informação, as composições matrimoniais desses possíveis arranjos, que uniram muitos migrantes e indígenas.

A materialidade desses arrazoados pode ser cruzada com os relatos coletados através das entrevistas, que igualmente revelaram através do índice analítico "união" ou "casamento" possibilidades para o entendimento da história do Purus, principalmente no que tange as características dos contatos. Do ponto de vista histórico esse é um eixo bastante significativo, pois ao analisarmos a composição social da população do rio percebe-se que existiu (e continua existindo) um forte processo de associação entre pessoas de origens e culturas diversas, indígenas e não indígenas, em sua heterogeneidade, que foi acelerado desde o vertiginoso avanço das frentes de expansão extrativistas nos oitocentos. 
Um testemunho bastante interessante e que corrobora com esta argumentação foi a do Sr. Feliciano Reis, residente em Tapauá e filho de maranhenses, que viveu a maior parte de sua vida trabalhando na lida extrativa. Desde criança acompanhava seu pai nos trabalhos na floresta, principalmente na coleta da sorva e da castanha, característica das feições da economia após o forte declínio da borracha. Além disso, em seu relato existem várias pistas da relação de contato entre indígenas e migrantes, sendo o pai do Sr. Feliciano um interlocutor, responsável pela tentativa de arregimentar indígenas Iafi (etnia que hoje é associada aos Banawá) para o trabalho de coleta.

Diante dessa empreitada, havia trocas culturais muito significativas. Primeiramente, os agentes "brancos" aproximavam-se oferecendo rancho ${ }^{v}$, contendo desde alimentos até ferramentas de trabalho diversas (terçados, facas, etc). Ocasião muitas vezes atravessada por diversos conflitos, mas que segundo Sr. Feliciano, também guardava espaços de negociação. Configurava-se, assim, uma relação de trocas, entre mercadorias e produtos extrativos, cuja base tinha no secular sistema de aviamento seu eixo principal.

Esse processo de trocas e arregimentação para o trabalho compreendia a presença de diversos agentes, inclusive, com o passar do tempo, dos próprios indígenas, que também foram abrindo novas frentes para exploração, conseguindo fontes de trabalhadores (indígenas e não indígenas). Tudo leva a crer que a labuta em troca das mercadorias, a relação patronal, o aprendizado da língua do outro (tanto por parte dos "brancos" como pelo lado dos indígenas), assim como os intercâmbios culturais diversos, transformavam de maneira decisiva os ritmos do cotidiano e do trabalho.

Aspectos semelhantes também foram anotados nos trajetos de pesquisa em Canutama, parada seguinte na rota da Expedição. Situada numa área de várzea, apenas com pequenos pontos de terra firme, a cidade 
foi no século XIX um importante entreposto de exploração do Purus, base para incursões que buscavam gêneros na floresta. Logo nos primeiros passos da pesquisa, tornou-se perceptível que a cidade guardava mais fontes documentais (oficiais) do que Tapauá. Nas primeiras investidas descobrimos o Arquivo Municipal, sediado no prédio da Prefeitura, onde existe um volume bastante significativo de documentos. Foram listados documentos da Intendência e da Prefeitura (de anos diversos a partir de 1906), ofícios, circulares, folhas de pagamento, atas, receitas do município, impostos municipais e alvarás, regulamentos para o serviço público e registros de impostos, com periodicidades diversas, de maneira geral, situadas entre o final do século XIX e os primeiros anos do XX. Esses fragmentos do passado têm sua produção ligada aos desígnios do poder, do Estado, dos olhares governamentais, que, ao contrário do que se poderia considerar apressadamente, não falam somente do palco decisório.

No ano de 1911, na mensagem dirigida à Intendência Municipal de Canutama, existe a oficialização de uma reclamação relacionada aos locais de moradia da maior parte da população da cidade, feita pelo então Superintendente Coronel Theodoro dos Reis Botinelly. De acordo com o Coronel Botinelly, os munícipes não estavam a par dos interesses das leis, construindo suas casas em áreas não permitidas, como as áreas de várzea. Portanto, era urgente a definição de meios para equacionar o problema diante dos "abusos" da população, pois todos deveriam habitar a área de terra firme como rezava os desígnios legais.

Um ponto Srs. Intendentes que reclama a atenção dos poderes competentes e que já é tempo de tratar-se delle, é o cumprimento da lei n. 22 de 10 de outubro de 1891 que creou o Município de Canutama.

Diz essa lei que a sede da Villa é na terra firme e que na várzea apenas haverão armazéns e o porto de embarque e desembarque.

Ora, por um abuso, a população tem-se concentrado toda na várzea, deixando a terra firme em quase completo abandono. 
É do cumprimento da minha administração o convergir as minhas vistas para a terra firme, empregando todos os meios e esforços para que aquella lei seja cumprida.vi

Percebe-se diante da fala oficial um posicionamento contrário aos habitantes da cidade, que insistiam no "abuso" de construírem suas habitações nas áreas de várzea. Acompanhando a tessitura da fonte, é importante destacar que no contexto da virada do século XIX e início do século XX havia uma preocupação generalizada dos poderes públicos com o ordenamento urbano, que consistia também numa tentativa de ordenamento social, desdobrando-se, desse modo, não somente nas ruas, mas também nos hábitos e na vida dos cidadãos.

Diante dessa problemática, ainda tratando dos desígnios "legais", foi encontrada no percurso da pesquisa uma tabela contendo informações sobre as cobranças de impostos para o ano de 1927, que pode ser verificado no livro de atas da Intendência Municipal de Canutama. Em tal documento estão contidas também algumas discussões sobre a composição urbana da época, nomeações de cargos, exonerações, definições do funcionamento do mercado público, folhas de pagamento, entre outros índices, que podem trazer a lume muitos e interessantes fragmentos do passado da cidade. No que tange a cobrança dos impostos, chama atenção a variedade de tipos de taxação, que além de incidirem nos empreendimentos comerciais, como botequins, também tributavam, por exemplo, pessoas empregadas na quebra de castanha, entre outras atividades.

Além da enumeração dos impostos, existe em anexo uma série de observações sobre interdições, portarias sobre os horários de funcionamento dos estabelecimentos e observações sobre a regularidade de construções, produtos e serviços. Pode-se inferir, nesse sentido, que existia uma tentativa concreta de controle e disciplinarização de um largo conjunto de relações sociais estabelecidas no espaço urbano, composto através de taxações e ordenações estipuladas para as mais diversas atividades. 
Um aspecto interessante a ser observado, indo além da leitura das taxações acima esboçadas, consiste num exame dos diversos ramos de trabalho e sistemas produtivos, pois é possível entrever uma significativa variedade de atividades empreendidas pela população (ou pelo menos ter uma ideia das suas possibilidades). Canutama, olhando por esse lado, aparece como um cenário urbano com atividades e serviços bastante variados, com engenhos movidos a vapor que fabricavam açúcar e cachaça, estaleiros para construção de embarcações de madeira, marchantes responsáveis pelo corte e distribuição de carne, coletores de castanha, além de quitandas, padarias, marcenarias, e até oficinas de ourivesaria. A variedade de serviços pode denotar a força dos fluxos econômicos da época, que por sua vez permitem vislumbrar algumas das características de uma sociedade de consumo monetarizada, que detinha ou mesmo buscava acompanhar os valores traçados no plano das grandes aglomerações urbanas.

Embora estejamos analisando a cidade no contexto de 1927, não seria inócuo inferir que tais facetas sejam ainda eco do período áureo da borracha, quando o Purus, até a década de 1910, fora o maior produtor da bacia amazônica. Contudo, mesmo sabendo que nos idos de 1920 não havia mais a força econômica de décadas anteriores, é importante não deixar de apontar certa efervescência em Canutama, principalmente no que diz respeito à pluralidade do seu contexto urbano e de suas atividades econômicas.

Por outro lado, tudo leva a crer que diante desse cenário multifacetado da economia alguns sujeitos eram empurrados para as “margens" do social, tendo seus hábitos, locais de moradia, e certamente também suas atividades produtivas afetadas, comprometidas perante as novas demandas de impostos e demais regulações públicas. Os desdobramentos das frentes pioneiras incidiam diretamente nesse cenário. As cidades passavam a ser bases para as explorações, entrepostos para os 
produtos destinados ao comercio, recebendo rotineiramente fluxos de mercadorias e pessoas envolvidas na labuta. Esses movimentos ajudavam a compor muitos dos desafios de alteridade, firmados através dos encontros entre modos de vida diversos. A própria noção de urbanidade, definida através de códigos de conduta, cobrança de impostos e demais regras, deve ser posicionada diante desse quadro conflituoso da alteridade, pois havia intenções impositivas de intervenção na vivencia dos outros, tentativas de adequação, entre outras medidas.

Estas referências também podem ser feitas quando tratamos de Lábrea, cidade localizada próxima da desembocadura do rio Ituxi, uma área riquíssima em gêneros extrativos e que concentrava grande parte da população que eventualmente circulava pela área entre os finais do século XIX e início do XX. Tal arrazoado pode ser lido de maneira mais concreta quando analisamos os testemunhos do Padre Francisco Leite Barbosa, que chegou à localidade em 1878, época ainda distante do auge da efervescência urbana encontrada no início do século XX em Canutama. O padre escreveu o que chamou de "Resumo Histórico da Paróchia", contando sua trajetória e seus enfrentamentos diários, arrolando informações sobre casamentos e batizados, além de listar os beneméritos que doavam recursos para a Igreja. Nesse testemunho, Francisco Leite confidencia que nos idos de 1878, tempos de sua chegada, a cidade era um local abandonado, sendo uma espécie de "feitoria de seringueiros, e um dos mais atrazados logares do rio Purus, não tendo barracão, nem logar especial onde podesse celebrar o Santo Sacrifício da missa."

Sua preocupação nesses primeiros tempos consistia em sedimentar um local para as celebrações religiosas, buscando angariar com as elites locais recursos para construir um templo. Além disso, esteve por muitas vezes singrando o rio Purus e seus afluentes buscando os seus "parochianos", fazendo suas desobrigas, ou seja, indo aos mais recônditos locais ministrar sacramentos, como batismos e casamentos. Os números 
desses trabalhos foram também arrolados como anexo em sua súmula sobre a história de Lábrea, discriminando os sacramentos, as datas e o sexo de seus catecúmenos. É possível vislumbrar através dos números a significativa atuação de Francisco Leite pelo rio, com um crescimento das atividades com o avançar dos anos.

O padre foi tecendo seus espaços de atuação relacionando-se com os chamados "coronéis", como Luís da Silva Gomes, grande seringalista do Ituxi, o maior contribuinte nas doações que propiciaram a construção da Igreja de Nossa Senhora de Nazaré em Lábrea, disponibilizando uma quantia de mais de dezessete contos de réis como consta no mesmo relatório de cunho histórico. É possível afirmar, nesse sentido, que as preocupações do religioso estavam estreitamente ligadas com os desígnios do poder local. Essa reflexão torna-se ainda mais plausível com a leitura dos números das desobrigas, que aparecem listados em linear ascensão, uma mostra do alcance das pregações do padre que alcançavam lugares cada vez mais distantes. Não por acaso, nessa mesma época, é possível também ver um avanço paulatino dos empreendimentos dos "coronéis", que levavam adiante as explorações pelo Purus através do regime de trabalho com base no sistema de aviamento.

Ao fazer alusão aos índios que viviam na floresta, principalmente aos que relutavam em aceitar a fé católica, Francisco Leite é bastante taxativo em relacioná-los a um ideário de barbárie e vadiagem, distante do trabalhador desejável. Para ele urgia uma ação mais firme de catequese dos indígenas, que poderia facilitar o trabalho de cristianização e defesa contra os "maus" costumes. Essas intenções podem ser analisadas também a partir do relato de cunho histórico que o padre deixou registrado.

Existem n'esse rio e em muitos de seus affluentes muitos índios rudes e pagãos, que precisão dos recursos da religião os quaes só poderão chegar até eles por intermédio de missionários, que os chamem e os aggremiem, afim de catechisal-os e instruil-os nos sãos princípios da fé christã. viii 
O trabalho de evangelização dos indígenas tinha um duplo objetivo. O primeiro vinculado à tarefa de arrebanhar almas para a fé cristã, e o segundo, que pode ser entendido como uma extensão do primeiro, de torná-los aptos a singrarem as águas da celebrada civilização e seus costumes. Era preciso, para tanto, fortalecer o trabalho de catequese, ao passo que os frutos dessa ação seriam colhidos à medida que os indígenas deixassem ou mesmo relegassem a um segundo plano seus referenciais culturais. Tendo em vista todos esses aspectos, não seria possível enxergar a relação de Francisco Leite com os "coronéis" através de uma ótica de isenção de interesses. Tudo leva a crer que havia uma relação de proximidade e cumplicidade entre ambos.

Esse tipo de associação tinha peso na conformação dos circuitos produtivos do rio. Além do trabalho de catequese com os indígenas, que almejava engrossar as fileiras de trabalhadores, existiam direcionamentos da produção extrativa que modificavam o cotidiano de muitos. A análise desse contexto pode ajudar no entendimento das relações patronais que existiram e que ainda permanecem na fala de muitos moradores do Purus. É preciso aprofundar o entendimento das dimensões coercitivas dos mundos do trabalho e seus desdobramentos, compreendendo suas formas cotidianas, que ainda fazem parte das lembranças que tramam os meandros da memória do Purus.

Entendemos que a tessitura histórica desses enredos com base em memórias podem apontar interessantes caminhos, especialmente indicando possibilidades de devassar o passado presente do rio. Nossos percursos, no barco e nas cidades de Tapauá, Canutama e Lábrea, ajudaram na elaboração dessa reflexão, sendo possível esboçar um painel de experiências históricas resguardadas nas fontes escritas e em narrativas de memórias. Neste breve artigo objetivamos apontar algumas questões, tendo como finalidade a 
contribuição com o debate sobre a vida guardada nas experiências dos que vivem e tecem cotidianamente a história do Purus.

\section{NOTAS}

i Organizada pelo Núcleo de Estudos da Amazônia Indígena (NEAI), cuja pesquisa foi apoiada pelo Projeto Saúde e Condições de Vida de Povos Indígenas na Amazônia, Programa de Apoio a Núcleos de Excelência PRONEX/FAPEAM/CNPq, Edital 003/2009 e pelo Instituto Brasil Plural (FAPEAM/CNPq).

ii Relatórios de Presidentes de Província (Império), Relatórios de Presidentes de Estado (República), documentos comerciais (Casa de Visconde de Santo Elias, Casa de J.G. Araújo, dentre outros).

iii Entrevista de Raimundo Nival - Tapauá, 12 de Janeiro de 2012. Por Admilton Freitas

iv Entrevista de Francisco, índio Paumari - Tapauá, 14 de janeiro de 2012. Por Admilton Freitas

v No Amazonas rancho, em geral, significa um conjunto de gêneros alimentícios, por vezes acompanhados também de utensílios de ferro, como terçados, facas, e outras ferramentas úteis para a lida na floresta.

vi Arquivo Municipal de Canutama. Livro de Registros de Decretos, Mensagens e Resoluções da Superintendência (1909 - 1917) - Mensagem apresentada a Intendência Municipal de Canutama, em sua primeira reunião de 1911 pelo Superintendente Coronel Theodoro dos Reis Botinelly.

vii Casa do bispo de Lábrea. Livro de Tombo da Freguesia de Nossa Senhora de Nazareh da Lábrea - 1902/1909.

viii Casa do bispo de Lábrea. Livro de Tombo da Freguesia de Nossa Senhora de Nazareh da Lábrea -

1902/1909.

\section{Referencias}

BENCHIMOL, Samuel. Amarônia: um pouco - antes e além depois. Manaus: Umberto Calderaro, 1977.

CUNHA, Manuela Carneira da e ALMEIDA, Mauro Barbosa de (Orgs.). Enciclopédia da floresta: práticas e conbecimentos das populações. São Paulo: Companhia das Letras, 2002.

FUNES, Eurípedes. El Dorado no Inferno Verde - "Quem vive no inferno se acostuma com os cães.” In: GONÇALVES, Adelaide; EYMAR, 
Pedro (Orgs.). Mais borracha para a Vitória. Fortaleza/Brasília: MAUCNUDOC/Ideal Gráfico, 2008.

GINZBURG, Carlo. Mitos, emblemas e sinais: morfologia e história. São Paulo: Companhia das Letras, 2007.

GOMES, Flávio dos Santos. e NEGRO, Antônio Luigi. Além das senzalas e fábricas: uma História Social do Trabalho. Tempo Social: Revista de Sociologia da USP. São Paulo, v.18, n.1, 2006.

KROEMER, Gunter. Cuxinara: O Purus dos indígenas - ensaio étnico-histórico e etnográfico sobre os indios do médio Purus. São Paulo: Loyola, 1985.

OLIVEIRA, João Pacheco. O caboclo e o brabo. In: SILVEIRA, Ênio et al. Encontros com a Civilização Brasileira. Rio de Janeiro: Civilização Brasileira, 1979.

PRAT'T, Mary Louise. Os olhos do império: relatos de viagem e transculturação. Bauru: EDUSC, 1999.

SANTOS, Gilton Mendes (Org.) Álbum Purus. Manaus: EDUA, 2011.

REIS, Arthur César Ferreira. O seringal e o seringueiro. Rio de Janeiro: Ministério da Agricultura, 1953.

SAYAD, Abdelmalek. Imigração on os Paradoxos da Alteridade. São Paulo: EDUSP, 1998.

WILLIAMS, Raymond. Marxismo e Literatura. Rio de Janeiro: Zahar, 1979. 